\title{
Eutanásia em pequenos animais em Teresina - PI
}

\section{Euthanasia in small animals in Teresina - PI}

\author{
Dêmis Carlos Ribeiro Menezes ${ }^{1 *}$; Ana Maria Quessada ${ }^{2}$; \\ Ana Luíza Silva Guimarães ${ }^{3}$; Ezequiel Cardoso Saraiva de Almeida ${ }^{1}$
}

\section{Resumo}

A eutanásia é um procedimento utilizado com freqüência em pequenos animais, com o objetivo principal de aliviar o sofrimento. Desta forma, realizou-se um levantamento sobre os motivos que levam um veterinário a indicá-la e quais são estes animais. Foram analisadas 17406 fichas, onde se observaram 166 eutanásias o que corresponde a $0,95 \%$. A percentagem de cães eutanasiados foi de $97,59 \%$ e a de felinos $2,41 \%$. Em relação à raça, $26,10 \%$ dos animais era sem raça definida, $20,48 \%$ pastor alemão, $9,04 \%$ fila brasileiro, $7,23 \%$ pequinês e $36,75 \%$ outras raças. Com respeito à idade, registrou-se que $60,84 \%$ tinham entre 0 e 3 anos, $15,06 \% 3$ e 6 anos, 4,82\% 6 e 9 anos, $4,22 \% 9$ e 12 anos, $1,20 \%$ acima de 12 anos e $13,86 \%$ idade desconhecida. Sobre o motivo da eutanásia, $64,60 \%$ dos animais foram eutanasiados devido à Leishmaniose Visceral Canina (calazar), 12,65\% devido a cinomose e 22,89\% devido a outras enfermidades. Concluiu-se que a maioria dos animais submetidos à eutanásia era jovem, ao contrário do que se observa em outros países. Além disso, inclui-se entre as principais causas de óbitos, enfermidades infecciosas que podem ser prevenidas por vacinação adequada.

Palavras-chave: Leishmaniose, cão, gato

\begin{abstract}
Euthanasia is a procedure frequently utilized in small animals with the objective to minimize suffering. In this way, it was realized the survey about reasons that leave the practitioner to realize the procedure and who are these animals. It was analyzed 17406 medical records. It was observed 166 euthanasia corresponding to $0.95 \%$. The percentage of the euthanazied dogs were $97.59 \%$ and $2.41 \%$ felines. In relation to breed $26.10 \%$ were mongrel dogs, $20.48 \%$ German sheepherd, $9.04 \%$ Brazilian fila, $7.23 \%$ Pekinese and $36.75 \%$ other breeds. In relation to age, it was observed that $60.84 \%$ have $0-3$ year, $15.06 \%$ $3-6$ year, $4.82 \% 6-9$ year, $4.22 \% 9-12$ year, $1.2 \%$ above 12 year and $13.86 \%$ unknown age. About the reason of the euthanasia, $64.60 \%$ was sacrificed due to visceral leishmaniosis (calazar), $12.65 \%$ due to distemper and $22.89 \%$ due to other diseases. It was concluded that the most animals submitted to euthanasia were young, differently of the other countries. Among principal death reasons, it was included also infectious diseases that can be prevented by adequate vaccination.
\end{abstract}

Key words: Leshmaniosis, dog, cat

\footnotetext{
1 Mestres em Ciência Animal pela Universidade Federal do Piauí-Email: anaedemis@ig.com.br; demiseana@universiabrasil.net

2 Prof $^{\mathrm{a}}$. da disciplina Clínica Cirúrgica Veterinária da Universidade Federal do Piauí

3 Médica Veterinária pela Universidade Federal do Piauí

* Autor para correspondência.
} 
Na sociedade moderna, os cães e os gatos estão conquistando a cada dia mais espaço como animais de companhia, tornando-se companheiros inseparáveis de seus proprietários, quiçá, os únicos. A clínica destes animais representa hoje uma importante fonte de renda para os médicos veterinários em Teresina. Portanto, estes profissionais necessitam de subsídios que os auxiliem a melhor exercer a sua profissão e a atender às expectativas de seus clientes.

Entre os procedimentos utilizados em medicina veterinária, está a eutanásia, utilizada com alguma freqüência em pequenos animais. Este procedimento pode ser utilizado com diversos objetivos, entre eles o alívio do sofrimento (RIVERA, 1996).

Discutem-se hoje, no país, leis que limitam a natalidade de cães agressivos, e embora suscite polêmica, há quem defenda a eutanásia deste tipo de cão, o que torna o tema extremamente atual.

A eutanásia é a morte provocada de maneira humanitária e misericordiosa de animais, executada por pessoas especialmente treinadas (McDONALD et al., 1978; HATCH, 1992), sob a responsabilidade de um médico veterinário de acordo com a resolução 714 do Conselho Federal de Medicina Veterinária de 20 de junho de 2002 (CONSELHO FEDERAL DE MEDICINA VETERINÁRIA, 2002).

O abandono dos animais pelos seus proprietários é uma das principais causas de eutanásia (ANIMAL SHELTER REPORTING STUD apud NASSAR; FLUKER, 1988; SNOOK, 1988; LORD et al., 1998; WHITE; SHAWHAM, 1996) com estimativa de 8 milhões de cães e gatos eutanasiados por ano nos Estados Unidos (ANIMAL SHELTER REPORTING STUDY apud NASSAR; FLUKER, 1988; LORD et al., 1998; WHITE; SHAWHAM, 1996). A eutanásia também pode ser indicada nos casos de lesões graves da medula espinhal em gatos (MORGAN, 1987).

No relacionamento entre veterinário e cliente, a eutanásia nunca deve ser realizada sem a autorização por escrito do cliente ou agente legal. Veterinários têm sido processados por clientes que negaram ter dado permissão verbal para a eutanásia de seus animais (HATCH, 1992).

Em um estudo nos Estados Unidos (EUA) com 93 cães agressivos, observou-se que 25 (27\%) foram eutanasiados devido ao comportamento (REISNER; ERB; HOUPT, 1994). Embora eles pudessem ser submetidos a tratamentos que eliminassem o problema (MILANI, 1997).

De acordo com pesquisa em 863 cães e gatos submetidos à eutanásia observou-se que a grande maioria foi em razão de senilidade (55\%), seguido de enfermidades terminais $(30 \%)$, trauma $(7 \%)$, problemas comportamentais $(5 \%)$ e animais saudáveis (3\%). O autor sugere mais estudos sobre o assunto, pois considera que alguns problemas comportamentais que levaram a eutanásia possuíam tratamento satisfatório (EDNEY, 1998).

$\mathrm{Na}$ Dinamarca as principais causas de eutanásia são problemas relacionados à idade $(29,6 \%)$ ou problemas comportamentais $(21,4 \%)$. Os autores relataram que os animais com problemas comportamentais não receberam qualquer tipo de terapia antes da eutanásia (MIKKELSEN; LUND, 2000).

Os animais deverão ser submetidos à eutanásia em ambiente tranqüilo e adequado e sob responsabilidade de um médico veterinário. A eutanásia de cães e gatos deve ser realizada com barbitúricos, anestésicos inaláveis, $\mathrm{CO} 2, \mathrm{CO}$ e cloreto de potássio com anestesia geral prévia. Em cães pode-se ainda utilizar a eletrocussão com sedação prévia (CONSELHO FEDERAL DE MEDICINA VETERINÁRIA, 2002).

Embora a eutanásia seja amplamente aplicada nos Hospitais e clínicas veterinárias brasileiras, não existem dados científicos confiáveis sobre os motivos que levam um proprietário a solicitar ou dar o seu consentimento para uma eutanásia. Tampouco se sabe com que freqüência ela é utilizada ou indicada 
pelos médicos veterinários no Brasil. Pretende-se, com este trabalho contribuir para esclarecimento deste tema na cidade de Teresina, a qual concentra a maior parte das clínicas veterinárias do Piauí, além de sediar o único curso de Medicina Veterinária do estado.

Realizou-se uma consulta às fichas da Clínica Médica e Cirúrgica de Pequenos Animais da Universidade Federal do Piauí (10.444 fichas), de abril de 1982 a dezembro de 2000, visando às fichas que continham eutanásia. Com o mesmo objetivo, também se visitou quatro clínicas particulares (6.962 fichas), sediadas em Teresina.

Foram coletados os dados referentes ao animal (espécie, raça sexo, idade), bem como a causa e o método utilizado na execução da eutanásia. Verificouse também, se os proprietários autorizavam por escrito a realização da eutanásia.

De um total de 17.406 fichas consultadas nas clínicas visitadas, foram registradas 166 fichas com casos de eutanásia, equivalente a 0,95\%. Em 97,59\% dos casos a eutanásia foi realizada em animais da espécie canina, sendo que os $2,41 \%$ restantes foram realizados em animais da espécie felina. Os resultados entre machos e fêmeas, são equivalentes, já que $54,22 \%$ dos animais submetidos à eutanásia eram machos, e $45,78 \%$ eram fêmeas.

Em relação à raça, 26,51\% dos animais eutanasiados não tinham raça definida (SRD), 20,48\% pertenciam a raça pastor alemão, 9,04\% eram fila brasileiro, 7,23\% eram pequinês e outras raças como doberman, dogue alemão, poodle, cooker spaniel, pincher, boxer e pit bul, apresentaram percentual entre $3 \%$ e $5 \%$, cada uma. O restante devido à baixa representatividade $(8,64 \%)$ se enquadrou em outras raças. Não foram encontrados dados semelhantes na literatura para que se pudesse realizar uma comparação. No entanto, chama a atenção o fato de que a raça pastor alemão tenha tão grande expressão.

Quanto à faixa etária, evidenciou-se que a maioria dos animais eutanasiados era jovem. A distribuição nas faixas etárias foi a seguinte: $60,84 \%$ possuíam de 0 a 3 anos de idade, $15,06 \%$ tinham entre 3 e 6 anos, $4,82 \%$ ficavam no intervalo de 6 a 9 anos, $4,22 \%$ tinham entre 9 e 12 anos, 1,20\% tinham acima de 12 anos e $13,86 \%$ possuíam idade desconhecida. Embora na Inglaterra (EDNEY, 1998) e Dinamarca (MIKKELSEN; LUND, 2000) tenha sido observado que os animais submetidos à eutanásia pertenciam à faixa etária mais elevada, no estudo em questão ficou evidenciado que os animais eutanasiados foram os da faixa etária mais baixa ( 0 a 3 anos). Provavelmente isto se deve ao fato de que no estudo em questão a maioria dos cães eutanasiados o foram devido a LVC, endêmica em Teresina.

No que se refere às causas, $64,46 \%$ dos animais foram submetidos à eutanásia por estarem acometidos de LVC e $12,65 \%$ por apresentarem cinomose. Outras enfermidades como tumor de mama, cirrose hepática, fratura de coluna, pneumonia, gastrenterite, amputação de membro, aumento de próstata e convulsão, representaram $6 \%$ no total. No restante dos casos $(13,58 \%)$ não havia registro das causas da eutanásia.

Em relação à eutanásia por cinomose e outras enfermidades (6\%), os resultados são semelhantes aos encontrados por Edney (1998) na Inglaterra $(30 \%)$.

A senilidade é a principal causa pela qual os pequenos animais são eutanasiados na Inglaterra (EDNEY, 1998) e Dinamarca (MIKKELSEN; LUND, 2000). Este motivo não foi observado nesta pesquisa. É difícil encontrar uma explicação para que não se observasse eutanásia por senilidade em Teresina. É possível que muitos médicos veterinários não façam o registro da eutanásia.

Nos Estados Unidos, Reisner, Erb e Houpt (1994) e Milani (1997) observaram que a agressividade é um importante motivo de eutanásia em cães. Neste estudo não se observou eutanásia por motivos comportamentais como o registro de outros países (EDNEY, 1998; MIKKELSEN; LUND, 2000). 
Em relação aos felinos, observou-se que não houve eutanásia por abandono conforme registrado por Animal Shelter Reporting Study (apud NASSAR; FLUKER, 1988); Lord et al. (1998); Snook (1988), White e Shawham (1996). Neste estudo foram registrados apenas 4 casos de felinos eutanasiados, sendo que em três destes, não foi possível a informação a respeito do que motivou a eutanásia. O outro caso ocorreu devido a trauma (fratura da coluna vertebral), o que condiz com a afirmação de Morgan (1987).

Embora não se observasse eutanásia por abandono nas clínicas veterinárias, esta causa foi bastante expressiva no CCZ (Centro de Controle de Zoonoses) (3788 cães abandonados por ano), o que está de acordo com diversos levantamentos sobre o assunto em outros países (ANIMAL SHELTER REPORTING STUDY, apud NASSAR; FLUKER, 1988; EDNEY, 1998; LORD et al., 1998; SNOOK, 1988; WHITE; SHAWHAM, 1996).

A utilização da associação de anestésicos gerais e cloreto de potássio para a realização de eutanásia em pequenos animais foi o procedimento registrado nas clínicas veterinárias do estudo em questão e difere do utilizado no CCZ. Neste, a eutanásia é realizada por método físico (choque elétrico a 220 volts) o que está de acordo com a resolução 714 do Conselho Federal de Medicina Veterinária (CONSELHO FEDERAL DE MEDICINA VETERINÁRIA, 2002). Sem dúvida, a associação de anestésicos gerais e cloreto de potássio é o método mais prático, além de ser o agente que melhor satisfaz os critérios para emprego na eutanásia, por causar perda rápida e suave da consciência, provocando morte de maneira humanitária e misericordiosa (McDONALD et al., 1978; HATCH, 1992).

Embora se afirme que a eutanásia nunca deve ser realizada sem a autorização por escrito do cliente ou agente legal (HATCH, 1992), esta conduta foi observada somente em uma das clínicas veterinárias visitadas. O tema merece reflexão por parte dos profissionais que trabalham nas clínicas, pois veterinários têm sido processados por clientes que negaram ter dado permissão verbal para a eutanásia de seus animais (HATCH, 1992).

Com base nos dados colhidos neste experimento, concluiu-se que:

- A maioria dos cães eutanasiados em Teresina era jovem;

- A LVC foi o principal motivo pelo qual os cães foram eutanasiados em Teresina;

- Enfermidades que podem ser prevenidas por vacinação adequada figuram entre as principais causas de óbitos por eutanásia de cães em Teresina;

- A maioria das clínicas veterinárias de Teresina não solicita autorização por escrito do proprietário para que seja realizada a eutanásia em pequenos animais.

\section{Referências}

CONSELHO FEDERAL DE MEDICINA VETERINÁRIA. Resolução n ${ }^{\circ} 714$ de 20 de junho de 2002. Dispõe sobre procedimentos e métodos de eutanásia em animais, e dá outras providências. Diário Oficial [da] Republica Federativa do Brasil, Brasília, 21 jun. 2002.

EDNEY, A. T. B. Reasons for the euthanasia of dogs and cats. Veterinary Record, London, v.143, n.4, p.114, 1998.

HATCH, R. C. Agentes usados para eutanásia. In: BOOTH, N. H.; McDONALD, L. E. Farmacologia e Terapêutica em medicina veterinária. 6.ed. Rio de Janeiro: Guanabara Koogan, 1992.p. 928-932.

LORD, K. L.; WITTUM, T. E.; NEER, C. A.; GORDON, J. C. Demographic and needs assessment survey of animal care and control agencies. Journal of the American Veterinary Medical Association, Schaumburg, v.213, n.4, p.483-487, 1998.

McDONALD, L. E.; BOOTH, N. H.; LUMB, W. V.; REDDING, R. W.; AWYER, D. C.; STEVENSON, L.; WASS, W. M. Report of the AVMA: Panel on Euthanasia. Journal of the American Veterinary Medical Association, Schaumburg, v.173, n.1, p. 59-72, 1978. 
MIKKELSEN, J.; LUND, J. D. Euthanasia of dogs due to behavioural problems: na epidemiological study of euthanasia of dogs in Denmark, whit a special focus on problems of aggression. European Journal of Companion Animal Practice, Paris, v.10, n.2, p.143-150, 2000.

MILANI, M. M. The No-kill Controversy. Journal of the American Veterinary Medical Association, Schaumburg, v.210, n.1, p. 26-27, 1997.

MORGAN, R. V. Emergências Neurológicas. In:

Manual de emergências para pequenos animais. São Paulo: Manole, 1987. p 84-85.

NASSAR, R.; FLUKER, J. pet population dynamics and community planning for animal welfare and animal control. Journal of the American Veterinary Medical Association, Schaumburg, v.198, n.7, p.1160-1164, 1988.
REISNER, I. R.; ERB, H. N.; HOUPT, K. A. risk factor for behavior-related euthanasia among dominant-aggressive dogs:110 cases (1989-1992). Journal of the American Veterinary Medical Association, Schaumburg, v.205, n.6, p. 855-863,1994.

RIVERA, E. A. B. Eutanásia. Revista do Conselho Federal de Medicina Veterinária, Brasília, ano 2, n.7, p14-16, 1996.

SNOOK, S. S. Euthanasia of Healthy Pets. (Letter). Journal of the American Veterinary Medical Association, Schaumburg, v.194, n.1, p.6, 1988.

WHITE, D. J.; SHAWHAN, R. Emotional Responses to Animal Shelter Workens to Euthanasia. Journal of the American Veterinary Medical Association, Schaumburg, v.208, n.6, p 846-849, 1996. 